\title{
Relationships between Body Weight Perception and Weight Management: Practices among Adolescents
}

\author{
Kshitiz Upadhyay Dhungel', Barsha Bhattarai² \\ Department of Nutrition and Dietetics \\ College of Applied Food and Dairy Technology \\ (CAFODAT)
}

1Professor, Department of Physiology, Janaki Medical College, Janakpurdham, Nepal

${ }^{2}$ Dietitian Officer, Human Organ Transplant Center, Ministry of Health, Government of Nepal

\section{ABSTRACT}

Background and Objectives: Overweight and obesity are highly prevalent in western countries and growing problems in developing countries. Weight loss behaviors are highly prevalent among adolescents, and body weight perception motivates weight control practices. The aim of this study is to investigate the relationships between actual body weight, body weight perception, and weight control practices among adolescents.

Material and methods: A questionnaire-based survey was used to collect data on anthropometric measurements, demographic information, weight perception and weight control practices from a sample of 200 male and female students ( 89 boys and 111 girls) aged between 13 and19 year old. The association between weight loss attempts and socio demographic factors, weight status and the weight perception were analyzed. Multivariable logistic regression analyses were performed to examine the predictors of misperception and its association with weight-related behaviors. Cohen's kappa was calculated to analyze the accuracy of body weight perceptions.

Results: This study revealed that prevalence of underweight was higher in girls than boys. In this study, $8 \%$ were underweight including 3.5\% severely underweight, $23.5 \%$ were overweight, $6 \%$ were obese and the rest of the participants (59\%) were of normal weight. Only $61.5 \%$ respondents perceived their weight correctly. Perception of $21.5 \%$ adolescents was underestimated and $16.5 \%$ were overestimated than their actual weight status. Almost one third of the respondents were in weight control interventions. Almost $11 \%$ boys and $33 \%$ girls attempted weight loss activities. The gender biasness was seen in weight control (statistically significant,$p$ value $=0.003$ ). Body weight perception was found significant ( $p$ value, 0.001) in relation to weight control behavior.

Conclusion: Body weight perceptions are not in agreement with actual weight in adolescents. This discrepancy is more marked in females who use a variety of weight control behaviors. These behaviors are motivated more apparently by perceived weight rather than actual body mass index.

Key words: Body weight, Perception, Overweight, Obesity, body mass index

\section{INTRODUCTION}

Adolescents represent around twenty percent of the world's population; it is a period of immense change. It involves a transition from childhood dependency to adult selfsufficiency [1]. Adolescence is an important period known as second windows of 
opportunity to break vicious cycle of malnutrition. Growth during adolescence is faster than at any other time in an individual's life except the first year [1].

Adolescents make significant developments in physical growth, cognition, identity, family, peers, and sexuality in order to achieve emancipation, identity formation, and assumption of functional roles [2]. Body image is a psychosocial dimension of body size that encompasses both perceptual and attitudinal factors and has been associated with eating disorders. In recent years, its association with overweight and obesity has been described [3-7]. It is recognized that individuals make decisions on lifestyle behaviors based on body weight perceptions (a dimension of body image). In Nepal, there is a large burden of under nutrition alongside increasing overweight and obesity. Overweight and obesity are highly prevalent in western countries and growing problems in developing countries like Nepal [1, 8-11]. For public health and clinical programs to be more effective, body image of undernourished and overweight people should be understood in the context of the influence of culture on body weight perceptions and on weight management behaviors [9-11].

Weight control behaviors are precipitated by body weight perception. Body weight perception refers to the personal evaluation of one's weight as "underweight" or "normal weight" or "overweight" irrespective of actual body mass index $[3,12]$. A large number of studies have indicated that children and adolescents misperceive their body weight status $[3,5,10-11]$. There is sparse literature on weight perception and weight loss practices of adolescents in Nepal. Appropriate body weight perception and good weight loss practices are estimated to be an important point of focus for the design and implementation of clinical and public health initiatives [6-9]. There is no literature found on weight perception and weight loss practices in Nepalese population. So this study is carried out to analyze the associations between the actual weight statuses, body weight perceptions with weight-management intentions of the adolescents of Nepal.

\section{MATERIAL AND METHODS}

This is a community based descriptive crosssectional study. The study was conducted among adolescents aged 13 years to 19 years in 2 higher schools of Kathmandu, Nepal by using convenience sampling technique. Of these schools, 1 was government and 1 was private schools and $50 \%$ of sample was collected from each school by using simple random sampling. The sample size was estimated by using following formulae:

Sample Size $(\mathrm{n})=\left[\mathrm{z}^{2} \cdot \mathrm{pq}\right] / \mathrm{d}^{2}$

Where,

$\mathrm{z}=$ critical value which is equal to 1.96 in two-tailed test

$\mathrm{pq}=1$ (No recorded prevalence)

$\mathrm{d}=$ absolute sampling error that can be tolerated and it is fixed at $10 \%$

The total sample size for the study will be 384

Non-response rate was taken as $5 \%$

Final sample size was: $400 * 0.5=200$

Data were collected after verbal consent of the participants and written consent taken from the parents and/or Principal of the school using a structured questionnaire. 
Measurement of height, weight and was recorded using standard procedure [13, 14]. A written consent and assent from the respondents were taken before interview and assessment.

Excel and SPSS were used for data entry, coding, decoding and analysis of data. Anthropometric data was transformed to BMI scores using WHO Anthro+ (version 3.2.2, January 2011) software application that provides global references for adolescents' growth and development. Data were reported as number and percentages for all the categorical variables.

The prevalence of overweight and obesity were calculated by sex and age according to the WHO BMI classifications. The corresponding unadjusted odds ratios (ORs) and 95\% confidence intervals (CI) for the prevalence of overweight, and obesity was determined by a multiple logistic regression model. The regression model includes age and nature of school as independent variables and was stratified by sex. A non-stratified version of the model was also performed to assess the main effect of sex. The percentage distributions of body weight perception (thin, normal, fat and unknown) were calculated by sex and BMI. The percentage of correct and incorrect (under, over, or correct) weight perception were calculated by sex, age, and BMI. The percentage of taking action to lose weight among all participants was calculated by sex, age, BMI, and weight perception. The percentage of specific weight loss practice among all the persons taking action to lose weight was compared between boys and girls. Cohen's kappa was calculated to analyze the perception accuracy. Following gold standard was used to compare the kappa value:

Table 1: Classification of Kappa Value

\begin{tabular}{|l|l|}
\hline Kappa value (\%) & Accuracy \\
\hline Less than 20 & Poor agreement \\
\hline 20 to 40 & Fair agreement \\
\hline 40 to 60 & Moderate agreement \\
\hline 60 to 80 & Good agreement \\
\hline 80 to 100 & Very good agreement \\
\hline
\end{tabular}

\section{RESULT}

Among total 200 samples 89 were male and 111 were female. 100 adolescents from government higher secondary school and 100 from private higher secondary school were involved in the study. The demographic details of the adolescent respondents of the study are presented in Table 2 .

Table 2: Demographic distribution of the respondent by age

\begin{tabular}{cccccc}
\hline Age (Years) & Male & Female & $\begin{array}{c}\text { Government } \\
\text { school }\end{array}$ & $\begin{array}{c}\text { Private } \\
\text { school }\end{array}$ & Total \\
\hline 13 & $\mathbf{1 0}$ & $\mathbf{1 2}$ & $\mathbf{1 2}$ & $\mathbf{1 0}$ & $\mathbf{2 2}$ \\
14 & $\mathbf{1 2}$ & $\mathbf{1 5}$ & $\mathbf{1 3}$ & $\mathbf{1 4}$ & $\mathbf{2 7}$ \\
15 & $\mathbf{1 8}$ & $\mathbf{1 6}$ & $\mathbf{1 5}$ & $\mathbf{1 9}$ & $\mathbf{3 4}$ \\
16 & $\mathbf{1 4}$ & $\mathbf{2 0}$ & $\mathbf{1 6}$ & $\mathbf{1 8}$ & $\mathbf{3 4}$ \\
17 & $\mathbf{1 4}$ & $\mathbf{1 7}$ & $\mathbf{1 3}$ & $\mathbf{1 8}$ & $\mathbf{3 1}$ \\
18 & $\mathbf{1 2}$ & $\mathbf{1 7}$ & $\mathbf{1 8}$ & $\mathbf{1 1}$ & $\mathbf{2 9}$ \\
19 & $\mathbf{9}$ & $\mathbf{1 4}$ & $\mathbf{1 3}$ & $\mathbf{1 0}$ & $\mathbf{2 3}$ \\
Total & $\mathbf{8 9}$ & $\mathbf{1 1}$ & $\mathbf{1 0 0}$ & $\mathbf{1 0 0}$ & $\mathbf{2 0 0}$ \\
\hline
\end{tabular}


Janaki Medical College Journal of Medical Sciences (2020); Vol.8 (1):40-49

Table 3: Distribution of total subjects based on- body weight perception accuracy

\begin{tabular}{|c|c|c|c|c|c|c|c|c|}
\hline \multirow[t]{2}{*}{ Weight perception } & \multicolumn{2}{|c|}{ Underweight } & \multicolumn{2}{|c|}{ Normal } & \multicolumn{2}{|c|}{ Overweight } & \multicolumn{2}{|c|}{ Total } \\
\hline & $\mathbf{N}$ & $\%$ & $\mathbf{N}$ & $\%$ & $\mathbf{N}$ & $\%$ & $\mathbf{N}$ & $\%$ \\
\hline Correct & 20 & 87 & 56 & 47.4 & 47 & 81 & 123 & 61.5 \\
\hline Underestimated & $\mathbf{0}$ & $\mathbf{0}$ & 32 & 27.1 & 11 & 19 & 43 & 21.5 \\
\hline Overestimated & 3 & 13 & 30 & 25.4 & $\mathbf{0}$ & $\mathbf{0}$ & 33 & 16.5 \\
\hline Total & 23 & 11.5 & 118 & 59 & 58 & 29 & 200 & 100 \\
\hline Kappa Value & & 82) & & 19) & & .8) & & \\
\hline
\end{tabular}

Table 4: Gender wise distribution of subjects based on weight perception accuracy

\begin{tabular}{|c|c|c|c|c|c|c|c|c|}
\hline \multirow[t]{2}{*}{ Weight perception } & \multicolumn{2}{|c|}{ Underweight } & \multicolumn{2}{|c|}{ Normal } & \multicolumn{2}{|c|}{ Overweight } & \multicolumn{2}{|c|}{ Total } \\
\hline & $\mathbf{N}$ & $\%$ & $\mathbf{N}$ & $\%$ & $\mathbf{N}$ & $\%$ & $\mathbf{N}$ & $\%$ \\
\hline \multicolumn{9}{|c|}{ Boys $(k, 0.62)$} \\
\hline & \multicolumn{2}{|c|}{$(k, 0.54)$} & \multicolumn{2}{|c|}{$(\mathrm{k}, 0.23)$} & \multicolumn{2}{|c|}{$(k, 0.64)$} & \multicolumn{2}{|c|}{$(k, 0.62)$} \\
\hline Correct & 4 & 66.6 & 34 & 61.8 & 20 & 71.4 & 58 & 65.2 \\
\hline Underestimated & 0 & 0 & 10 & 18.2 & 8 & 28.6 & 18 & 20.2 \\
\hline Overestimated & 2 & 33.3 & 11 & 20 & 0 & 0 & 13 & 14.6 \\
\hline Total & 6 & 6.7 & 55 & 61.7 & 28 & 31.4 & 89 & 100 \\
\hline \multicolumn{9}{|c|}{ Girls $(k, 0.48)$} \\
\hline & \multicolumn{2}{|c|}{$(\mathrm{k}, 0.91)$} & \multicolumn{2}{|c|}{$(k, 0.16)$} & \multicolumn{2}{|c|}{$(k, 0.86)$} & \multicolumn{2}{|c|}{$(\mathrm{k}, 0.48)$} \\
\hline Correct & 16 & 94.1 & 22 & 34.9 & 27 & 87 & 65 & 58.5 \\
\hline Underestimated & 0 & 0 & 22 & 34.9 & 4 & 13 & 26 & 23.4 \\
\hline Overestimated & 1 & 5.9 & 19 & 30.2 & 0 & 0 & 20 & 18.1 \\
\hline Total & 17 & 15.3 & 63 & 56.7 & 31 & 28 & 111 & 100 \\
\hline
\end{tabular}

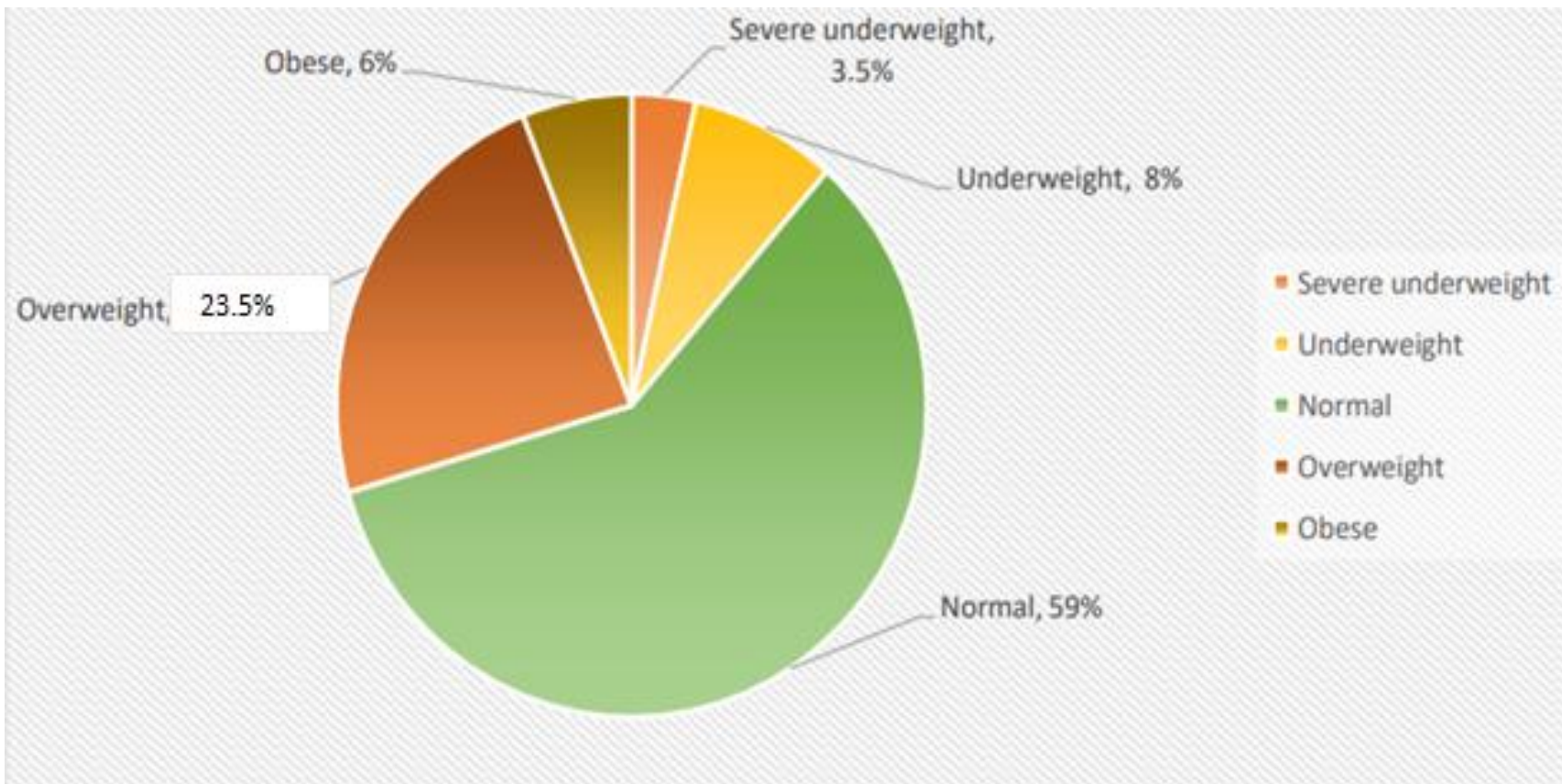

Figure 1: Weight status based on BMIz [Body mass index (BMI) for age z-score recommended by WHO] 
The mean BMI was found 21.2 \pm 13.4 . Figure one shows the Weight status based on Body mass index (BMI) for age z-score recommended by WHO [BMIz]. Eight percent (8\%) were underweight including 3.5\% severely underweight, $23.5 \%$ were overweight, $6 \%$ were obese and the rest of the participants (59\%) were of normal weight (Figure 1). Table 3 shows the gender wise distribution of total subject based on body weight perception accuracy and Table 4 shows the overall distribution with Kappa value. Weight perception accuracy of boys was moderate (Kappa value: $\mathrm{k}, 0.62$ ) and was more than the perception accuracy of female (Kappa value: k, 0.48). Only 61.5\% respondents perceived their weight correctly. Perception of $21.5 \%$ adolescents was underestimated and $16.5 \%$ were overestimated than their actual weight. Eighty seven (87\%) underweight respondent correctly perceived their weight and 13\%

Table 5: distribution of respondents by weight control behavior

\begin{tabular}{|c|c|c|c|c|}
\hline \multirow[t]{2}{*}{ Variables } & \multicolumn{2}{|c|}{$\begin{array}{l}\text { Attempted } \\
\text { Weight loss }\end{array}$} & \multirow[t]{2}{*}{$\begin{array}{l}\text { Unadjusted Odd } \\
\text { Ratio }(95 \% \mathrm{CI})\end{array}$} & \multirow[t]{2}{*}{$\begin{array}{c}\text { P- } \\
\text { value }\end{array}$} \\
\hline & Yes & No & & \\
\hline \multicolumn{5}{|l|}{ Gender } \\
\hline Male & $11(12 \%)$ & $78(88 \%)$ & 0.8 & \multirow[t]{2}{*}{0.003} \\
\hline Female & $33(30 \%)$ & $78(70 \%)$ & 1 & \\
\hline \multicolumn{5}{|l|}{ Age category } \\
\hline 13-15 Years & $7(8 \%)$ & $76(92 \%)$ & 1.3 & \multirow[t]{2}{*}{0.002} \\
\hline 16-19 Years & $37(32 \%)$ & $80(68 \%)$ & 0.5 & \\
\hline \multicolumn{5}{|l|}{ School } \\
\hline Private & $28(28 \%)$ & $72(72 \%)$ & 1.1 & \multirow[t]{2}{*}{0.06} \\
\hline Government & $16(16 \%)$ & $84(84 \%)$ & 0.9 & \\
\hline \multicolumn{5}{|c|}{ Actual weight status } \\
\hline Underweight & $2(9 \%)$ & $21(91 \%)$ & 0.4 & \multirow[t]{4}{*}{0.003} \\
\hline Normal & $12(10 \%)$ & $106(90 \%)$ & 0.7 & \\
\hline Overweight & $21(46 \%)$ & $25(54 \%)$ & 1.6 & \\
\hline Obesity & $9(75 \%)$ & $3(25 \%)$ & 1.9 & \\
\hline \multicolumn{5}{|c|}{ Own perception on weight } \\
\hline Very thin & $0(0 \%)$ & $21(100 \%)$ & NA & \multirow[t]{5}{*}{0.001} \\
\hline Thin & $0(0 \%)$ & $33(100 \%)$ & NA & \\
\hline Normal & $2(3 \%)$ & $66(97 \%)$ & 0.6 & \\
\hline Fat & $25(44 \%)$ & $32(56 \%)$ & 1.3 & \\
\hline Very fat & $19(90 \%)$ & $2(10 \%)$ & 1.4 & \\
\hline \multicolumn{5}{|c|}{ Parents' perception on weight } \\
\hline Very thin & $0(0 \%)$ & $22(100 \%)$ & 1.4 & \multirow[t]{5}{*}{0.004} \\
\hline Thin & $1(2 \%)$ & $42(100 \%)$ & 1.4 & \\
\hline Normal & $6(6 \%)$ & $93(94 \%)$ & 0.6 & \\
\hline Fat & $14(44 \%)$ & $18(56 \%)$ & 1.3 & \\
\hline Very fat & $2(50 \%)$ & $2(50 \%)$ & 1.4 & \\
\hline
\end{tabular}


overestimated their weight. The perception was found as almost perfect accuracy $(\mathrm{k}$, 0.82) [Table 3]. Similarly, only $47.4 \%$ respondents having normal weight status correctly perceived their weight. $27.1 \%$ adolescents having normal weight status underestimated their weight and25.4\% overestimated their weight. The perception accuracy was found slightly align with actual BMI (k 0.19) among normal adolescents [Table 3]. Similarly, 81\% overweight adolescents perceived their weight correctly whereas $19 \%$ of them felt as normal or underweight (underestimated). The perception accuracy of overweight subjects was found almost perfect (k 0.8) [Table 3].

When perception accuracy was observed gender wise slightly more than sixty-five percent $(65.2 \%)$ boys accurately perceived their weight followed by $20.2 \%$ underestimation and $14.6 \%$ overestimation. The overall perception accuracy of boys was found to be moderate (k 0.62). About sixtyseven percent $(66.6 \%)$ underweight boys perceived their weight correctly and 33.3\% overestimated their weight. The perception accuracy of underweight boys was found moderate (k 0.54). About sixty-two percent (61.8\%) normal boys perceived them correctly whereas $18.2 \%$ underestimated and $20 \%$ overestimated. Normal weight boys fairly accurately perceived their weight themselves ( $\mathrm{k}$ 0.23). Almost seventy-two (71.4\%) percent overweight boys perceived them correctly and $28.6 \%$ felt them as normal/underweight (underestimated). The perception accuracy of overweight boys was moderate (k 0.64). Almost fifty-nine percent (58.5\%) girls accurately perceived their weight followed by $23.4 \%$ underestimation and $18.1 \%$ overestimation. The overall perception accuracy was found to be moderate (k 0.48). Among underweight girls,
94.1\% perceived them correctly and the perception accuracy was almost perfect $(\mathrm{k}$ 91). But only $34.9 \%$ girls having normal weight status perceived them as normal. $30.2 \%$ felt them as overweight and 34.9\% underestimated their weight. Perception of own weight of girls having normal weight status was poorly accurate (k 0.16). Eighty seven percent overweight girls perceived them correctly and the perception accuracy was almost perfect ( $\mathrm{k} \mathrm{0.86)}$. The perception accuracy was found slightly higher in boys then in girls [Table 3 \& 4].

Body weight perception and weight control behavior is shown in Table 5. Almost one third of the respondents were in weight control interventions. $11 \%$ boys and 33\% girls were attempted weight loss activities in last 3 months. The gender biasness in weight control was found statistically significant ( $p$ value, 0.003). Actual weight status of weight perception directly leads to weight loss ( $p$ value, 0.003 ) . Body weight perception was found significant in relation to weight control behavior. Parents' weight perception also played significant role in weight control measures [Table 5].

\section{DISCUSSION}

In this study, $8 \%$ were underweight including $3.5 \%$ severely underweight, $23.5 \%$ were overweight, $6 \%$ were obese and the rest of the participants (59\%) were of normal weight based on body mass index (BMI) for age z-score recommended by WHO (figure 1). Underweight was found statistically different in boys and girls. According to the adolescent nutrition survey conducted by NHRC [15], 42.2\% adolescent aged 15-19 years were under weight and $1.8 \%$ was obese in Nepal. This study revealed that prevalence of underweight were higher in girls than boys but the findings of the study done in Lalitpur, 
indicated that prevalence of underweight was slightly more in male $(2.4 \%)$ than in female $(1.9 \%)[16]$.

Among the subjects, $47.5 \% \quad(56 / 118)$ perceived themselves as having a normal weight whereas $59 \%$ of total respondents were normal. The Malaysia School Based Nutrition Survey 2012, which included a body weight perception questionnaire and anthropometric measurements, compared actual and perceived body weight status, the findings show that $13.8 \%$ of adolescents underestimated their weight, $35.0 \%$ overestimated, and $51.2 \%$ correctly judged their own weight [13].

In this study, only $61.5 \%$ respondents perceived their weight correctly. Perceptions of $21.5 \%$ adolescents were underestimated and $16.5 \%$ were overestimated than their actual weight status. $87 \%$ underweight respondent correctly perceived their weight and $13 \%$ overestimated their weight. The perception of underweight adolescents was found as almost perfect accuracy (k 0.82). Similarly, only $47.4 \%$ respondents having normal weight status correctly perceived their weight. $27.1 \%$ adolescents having normal weight status underestimated their weight and $25.4 \%$ overestimated their weight. The perception accuracy of normal weight was found slightly align with actual BMI (k 0.19). 81\% overweight and obese was perceived their weight currently whereas $19 \%$ of them felt as normal or underweight (underestimated). The perception accuracy of overweight subjects was found almost perfect (k 0.8) [Table 3].

Bhurtun et. al. [4] found gender differences in body weight perception among their study subjects, they also observed that the weightloss behaviours was more among girls than their male counterpart which is similar to the finding of this study [Table 5]. They also reported that the body weight perception was poorly associated with actual weight status which is in contrast to what is seen in our study.

When observed gender wise, slightly more than sixty-five percent $(65.2 \%)$ boys of our study accurately perceived their weight followed by $20.2 \%$ underestimation and $14.6 \%$ overestimation. The overall perception accuracy of boys was found to be moderate $(\mathrm{k}$ 0.62) [Table 4]. About sixty-seven percent (66.6\%) underweight boys perceived their weight correctly and $33.3 \%$ overestimated their weight. The perception accuracy of underweight boys was found moderate $(\mathrm{k}$ 0.54). About sixty-two percent (61.8\%) normal boys perceived them correctly whereas 18.2\% underestimated and 20\% overestimated. Normal weight boys fairly accurately perceived their weight themselves (k 0.23). Almost seventy-two (71.4\%) percent overweight boys perceived them correctly and $28.6 \%$ felt them as normal/underweight (underestimated). The perception accuracy of overweight boys was moderate ( $\mathrm{k}$ 0.64). Almost fifty-nine percent (58.5\%) girls accurately perceived their weight followed by $23.4 \%$ underestimation and 18.1\% overestimation. The overall perception accuracy of girls was found to be moderate (k 0.48). Among underweight girls, 94.1\% perceived them correctly and the perception accuracy was almost perfect $(\mathrm{k}, 0.91)$. But only $34.9 \%$ girls having normal weight status perceived them as normal. $30.2 \%$ felt them as overweight and $34.9 \%$ underestimated their weight. Perception of own weight of girls having normal weight status was poorly accurate (k 0.16). Eighty seven percent overweight girls perceived them correctly and the perception accuracy was almost 
perfect ( $\mathrm{k}$ 0.86). The perception accuracy was found slightly higher in boys then in girls [Table 3 \& 4].

One of the studies done in Bahrain adolescents shows that there is significant discrepancy between adolescents' perception of body weight and actual BMI. There was a tendency for adolescents to underestimate their weight status, which was especially noteworthy among the overweight and obese. More than half of the girls and about onethird of the boys expressed discontent with their current body weight [17]. Another study done by Wang et. al. in China [6] indicated that $19.8 \%$ of these youth perceived themselves as underweight, $57.8 \%$ as normal weight, and $22.4 \%$ as overweight. In reality, $4.9 \%$ were underweight, $64.3 \%$ were normal weight, and $30.8 \%$ were overweight. Furthermore, approximately $66.4 \%$ of these Chinese youth correctly perceived their body image, 28.2\% underestimated their true body image, and $5.4 \%$ overestimated their weight status [6].

As per Malaysia School Based Nutrition Survey, significantly more normal weight girls felt they were overweight, whereas significantly more overweight boys perceived themselves as underweight [7]. Similarly in a study done by Wang et. al. in China [6] girls were more likely than boys to overestimate their weight. Similar report was seen in southern California. More females perceived themselves as overweight and tried to control their weight, whereas more males tried to gain weight or never tried to control their weight $(p<0.001)$ [18].

Almost one third of the respondents were in weight control interventions. Eleven percent (11\%) boys and 33\% girls attempted weight loss activities in last 3 months. The gender biasness was seen in weight control behavior of the participants and was found statistically significant ( $p$ value, 0.003, Table 5). More students of age group 16-19 years (32\%) attempted weight loss behavior than the students of lower age group ie. 13-15 years (8\%). Likewise, more females (30\%) attempted weight loss behavior than their male counterpart (12\%). Actual weight status of weight perception directly leads to weight loss behavior shown by odd ratio upto 1.9 at 95\% CI ( $\mathrm{p}$ value, 0.003 ) as shown in Table 5.

Own body weight perception of the subjects was found to have significant relation on weight control behavior. Parents' weight perception also played significant role in weight control measures [Table 5]. Among the cohort, more overweight than nonoverweight students expressed a desire to lose weight. There was a significant relationship between perceived weight and weight control behaviors, such that females who perceived themselves as overweight were more likely to exercise. As per Malaysia School Based Nutrition Survey (3), significantly more normal weight girls felt they were overweight, whereas significantly more overweight boys perceived themselves as underweight. The overall appropriateness of weight control practices to body weight was $72.6 \%$. Adolescents attempting to lose or gain weight need to have better understanding toward desirable behavioral changes. According to Frank et. al. [11], adolescents of both sexes who perceived their body weight as below the expected weight took more initiatives to gain weight, and those who perceived themselves as overweight made more efforts to lose weight. In adolescents who perceived themselves as overweight, the behavior of not taking medication was associated with the outcome only in boys, whereas in girls, an association 
was observed with the variables eating less, cutting calories, or avoiding fatty foods aiming to lose or avoid increasing body weight. Adolescents of both sexes who practiced exercises were more likely to perceive themselves as overweight.

Inappropriate perceptions about body weight leads to increase in the problems related to overweight/obesity. Children are likely to attempt weight loss in India irrespective of their weight status, age and gender. Children who were actually overweight as well as those who were perceived by themselves to be overweight or obese were highly likely to try to lose weight as seen in study in south India [10] which is somewhat similar to the finding of this study.

\section{CONCLUSION}

Prevalence of overweight and obesity among adolescents is in increasing trends. Body weight perception was poorly associated with BMI among adolescents. Gender biasness was seen in the weight perceptions, with many more female adolescents overestimating their body size. Adolescents who perceived themselves as overweight engaged in weight reducing activities. Weight misperception is a determinant of healthy and unhealthy weightrelated behaviors. It is such that females who perceived themselves as overweight were more likely to exercise. Males who perceived themselves as overweight or who were actually (estimated to be) overweight, were more likely to exercise. This double-edged problem of weight misperception needs to be addressed by appropriate awareness programs from health care providers as well as from the media.

Further study of body weight perception, a weight status and weight management practice with large sample size is recommended. Similarly, role of cofounders in weight perception and control measures could also be studied and analyzed.

\section{ACKNOWLEDGEMENTS}

Authors would like to express their gratefulness to Dr. Kalpana Tiwari, Research Director of CAFODAT, Deepak Thapa, Director of NTAG, Mr. KP Lamsal, Nutrition specialist of SUAAHARA for providing necessary facilities and support to complete this work.

\section{REFERENCES}

1. Organization WH. Adolescent Nutrition: A Review of the Situation in Selected South-East Asian Countries. Geneva: World Health Organization; 2006.

2. Wu Y. The growing burden of overweight and obesity in contemporary China. In: Huxley R, editor. : CVD Prevention and Control 2009. p. 19-26.

3. Maruf FA, Akinpelu A0, Nwankwo MJ. Perceived body image and weight: discrepancies and gender differences among University undergraduates. African health sciences. 2012;12(4):464-72.

4. Bhurtun DD, Jeewon R. Body Weight Perception and Weight Control Practices among Adolescents \%J ISRN Nutrition. 2013;2013:6

5. Martin MA, May AL, Frisco ML. Equal Weights but Different Weight Perceptions among US Adolescents. Journal of Health Psychology. 2010;15(4):493-504

6. Wang Y, Liu H, Wu F, Yang X, Yue M, Pang Y, et al. The association between BMI and body weight perception among children and adolescents in Jilin City, China. PLOS ONE 2018;13(3):e0194237.

7. Zainuddin AA, Manickam MA, Baharudin A, Omar A, Cheong SM, Ambak R, et al. Self-Perception of Body Weight Status and Weight Control Practices Among Adolescents in Malaysia. 2014;26(5_suppl):18S26S

8. Nepal Demographic and Health Survey 2016: Key Indicators. In: Ministry of Health NNEaI, editor. Kathmandu, Nepal: Ministry of Health, Nepal. 2017

9. Cai L, Han X, Qi Z, Li Z, Zhang Y, Wang P, et al. Prevalence of Overweight and Obesity and Weight Loss Practice among Beijing Adults, 2011. PLOS ONE. 2014;9(9):e98744.

10. Swaminathan S, Selvam S, Pauline M, Vaz M. Associations between body weight perception and 
weight control behaviour in South Indian children: a cross-sectional study. 2013;3(3).

11. Frank R, Claumann GS, Felden ÉPG, Silva DAS, Pelegrini A. Body weight perception and body weight control behaviors in adolescents. Jornal de Pediatria. 2018;94(1):40-47.

12. Zhou X, Ji L, Ran X, Su B, Ji Q, Pan C, et al. Prevalence of Obesity and Its Influence on Achievement of Cardiometabolic Therapeutic Goals in Chinese Type 2 Diabetes Patients: An Analysis of the Nationwide, Cross-Sectional 3B Study. PLOS ONE. 2016;11(1):e0144179.

13. Upadhyay-Dhungel, K., \& Ghimire, S. Food Selectivity, Mealtime behavior, Weight status and Dietary intake in Children and adolescent with Autism. Janaki Medical College Journal of Medical Science 2019; 7(2): 48-65. https://doi.org/10.3126/imcjms.v7i2.30694.

14. Upadhyay Dhungel K, Adhikari B. Overweight and obesity and associated factors among medical representatives in Kathmandu valley. Janaki Medical College Journal of Medical Science 2019; 7(1):25-35.

15. Aryal KK MR, Chalise B, Mehata S, Sapkota F, Dhimal M, Jha BK, Karki KB. . Adolescent Nutrition Survey in Nepal, 2014. In: Council NHR, editor. Kathmandu, Nepal: Nepal Health Research Council; 2016.

16. Paudel S, Limbu NPM, Pradhan PMS, Shrestha SM, Shah AK, Daha SK, et al. Nutritional Status of Adolescents in Semi-urban Community in Dukuchhap Village of Lalitpur, Nepal. . BJHS 2017;2 (1):110-6.

17. Al-Sendi AM, Shetty P, Musaiger AO. Body weight perception among Bahraini adolescents. 2004;30(4):369-76.

18. Jaclyn B. Gaylis, Susan S. Levy \& Mee Young Hong (2020) Relationships between body weight perception, body mass index, physical activity, and food choices in Southern California male and female adolescents, International Journal of Adolescence and Youth, 2020; 25:1,: 264-275. DOI: $10.1080 / 02673843.2019 .1614465$

\section{Correspondence to: \\ Prof. Kshitiz Upadhyay Dhungel \\ Department of Physiology Janaki Medical College, Janakpurdham Nepal \\ kistiz2003@gmail.com}

